\title{
LEI DE WAGNER, ILUSÃO FISCAL E CAUSALIDADE ENTRE RECEITAS E DESPESAS: UMA ANÁLISE DAS FINANÇAS PÚBLICAS BRASILEIRAS
}

\author{
Pedro Henrique Martins Prado* \\ Cleomar Gomes da Silva ${ }^{\dagger}$
}

\begin{abstract}
Resumo
Este estudo investiga a dinâmica dos gastos do governo brasileiro baseando-se em três abordagens: a Lei de Wagner, a Ilusão Fiscal e o nexo causal com as receitas. Para o período 1997T1-2013T4 foram estimados Modelos Autorregressivos de Defasagens Distribuídas (ARDL) aplicados ao arcabouço da cointegração. Os resultados indicaram: i) indícios contra a validade da Lei de Wagner; ii) presença de Ilusão Fiscal, relacionada à existência de tributação indireta; iii) relação diferenciada da causalidade receitas-despesas, a depender da desagregação dos gastos públicos; iv) relação positiva entre salário mínimo real e dinâmica das despesas.
\end{abstract}

Palavras-chave: Despesas Públicas; Lei de Wagner; Ilusão Fiscal; ARDL.

\begin{abstract}
This article analyses the dynamics of government spending in Brazil, based on three approaches: Wagner's Law, Fiscal Illusion, and the causality between tax and spend. For the period 1997Q1-2013Q4, we estimate a series of Autoregressive Distributed Lag (ARDL) Bounds Testing Approach to Cointegration. The main results are: i) nonvalidity of Wagner's Law; ii) Fiscal Illusion, probably due to indirect taxes; iii) causality between tax and spend depending on how the public spending is broken down; iv) a positive relationship between real minimum wage and public spending.
\end{abstract}

Keywords: Public Expenditures; Wagner's Law; Fiscal Illusion; ARDL. JEL classification: C22; E62; H60.

DOI: http://dx.doi .org/10.11606/1980-5330/ea133508

\footnotetext{
*Universidade Federal de Uberlândia. E-mail: pradophm@ufu.br.

† Universidade Federal de Uberlândia \& Pesquisador CNPq. E-mail: cleomargomes@ufu.br.
} 


\section{Introdução}

O papel e o tamanho do Estado são explorados a partir de diferentes perspectivas na literatura econômica. Uma análise profunda, no entanto, exige não só entender os determinantes do tamanho em certo momento do tempo, mas também investigar sua dinâmica temporal. Uma primeira explicação foi proposta por Adolph Wagner no final do século XIX. No que ficou conhecido como Lei de Wagner, há uma relação positiva entre crescimento do setor público e renda nacional. Significa que a tendência de longo prazo de aumento mais que proporcional das despesas governamentais, em relação à produção, ocorre porque a elevação da renda nacional fomenta o crescimento da demanda por bens e serviços providos pelo Estado.

Já a abordagem sugerida pela Escola da Escolha Pública é baseada no entendimento de que as decisões a respeito do orçamento são tomadas a partir da interação de interesses conflitantes dos ofertantes (gestores) e dos demandantes de bens e serviços do setor público (eleitores-contribuintes). Porém, os gestores são capazes de manipular a estrutura fiscal para induzir os eleitores-contribuintes a superdimensionar benefícios e subdimensionar custos dos bens e serviços providos pelo Estado, induzindo-os à escolha de uma cesta de gastos e tributos diferente daquela desejável sob informações corretas. Esse efeito ficou conhecido como Ilusão Fiscal.

Por outro lado, no quarto final do século XX, ganha força outra frente de análise da dinâmica das despesas do setor público. Com o crescimento do déficit orçamentário do governo americano, parcela importante dos trabalhos na área de finanças públicas passa a se concentrar na temática da relação de causalidade entre os processos decisórios de arrecadação e de gasto do governo. Quatro hipóteses alternativas são apresentadas: i) "arrecadar e gastar" (taxspend), que sugere que o governo gastará conforme houver recursos disponíveis; ii) "gastar e arrecadar" (spend-tax), na qual os governos gastam primeiramente e, em seguida, buscam ampliar suas receitas fiscais de modo a financiar suas despesas; iii) "sincronização fiscal", isto é, despesas e receitas são alteradas simultaneamente; e iv) "neutralidade fiscal", que indica a existência de uma separação institucional entre as decisões de arrecadação e dispêndio.

Avançar a agenda de pesquisa a respeito dos determinantes da dinâmica das despesas públicas é importante e tornou-se ainda mais essencial com a centralidade que o debate acerca da condução orçamentária, da alocação eficiente dos recursos públicos e da estrutura de tributação tem ganhado no atual cenário de acentuada deterioração das contas públicas e de estagnação da atividade econômica brasileira. A Lei de Wagner, o impacto da Ilusão Fiscal e o nexo causal entre receitas e despesas são discussões significativas na análise das finanças públicas, de forma que há a necessidade de novos trabalhos nessas áreas de pesquisa, uma vez que a literatura existente para o caso brasileiro é relativamente escassa e, por conseguinte, não permite um debate apropriado a respeito da validade dessas explicações.

Ademais, é salutar que os estudos empíricos sobre o dispêndio público no Brasil considerem a possibilidade de os gastos obrigatórios do governo terem dinâmica distinta dos gastos discricionários. Como discutido na Seção 3, as despesas primárias do governo central podem ser divididas em dois grupos com características profundamente distintas: por volta de $25 \%$ dos gastos são discricionários, isto é, podem ser facilmente alterados conforme a vontade do gestor; enquanto os demais gastos apresentam fortes regras e vinculações orça- 
mentárias, de modo que possuem rigidez acentuada e dinâmica "autônoma". Logo, as análises devem considerar os dois tipos de despesas separadamente, já que a utilização exclusiva de dados agregados pode prejudicar seriamente as conclusões. Por outro lado, em termos propositivos, é imprescindível compreender as diferenças de comportamento e de determinantes das dinâmicas dos distintos gastos para alterar adequadamente a alocação dos recursos entre as diferentes áreas.

Portanto, o objetivo deste trabalho é analisar a dinâmica dos gastos primários do governo central brasileiro (Governo Federal, Banco Central e INSS) entre o primeiro trimestre de 1997 e o quarto trimestre de 2013, levando em consideração a relação com as receitas governamentais e a possibilidade de presença de Ilusão Fiscal e de validade da Lei de Wagner. A investigação foi limitada a esse período devido ao fato de as fortes flutuações nos trimestres seguintes, que podem ser observadas nas análises preliminares deste estudo, estarem profundamente ligadas às alterações na contabilidade do governo, de maneira que os dados para 2014-2015 não refletem a realidade com fidelidade e tornam os parâmetros estimados instáveis.

No presente estudo, opta-se por considerar conjuntamente os três fatores em virtude do entendimento de que, mesmo sendo tão díspares, todas as explicações podem ser relevantes, de modo que ignorar uma delas conduziria a conclusões imprecisas e/ou incompletas. Adicionalmente, a captação dos diferentes fenômenos permite uma caracterização mais ampla do processo que determina a dinâmica dos gastos, pois possibilita verificar como os efeitos podem estar se retroalimentando. Por fim, apesar das diferenças, a abordagem adotada não é incompatível com a literatura existente, dado que trabalhos empíricos acerca do nexo causal entre receitas e despesas públicas captam indiretamente efeitos de Ilusão Fiscal e validade da Lei de Wagner (Chang \& Chiang 2009, Silva et al. 2010, Gadelha 2011, Elyasi \& Rahimi 2012, Rahman \& Wadud 2014, Saunoris 2015).

Para alcançar o objetivo proposto, são estimados Modelos Autorregressivos de Defasagens Distribuídas (ARDL) aplicados ao arcabouço da cointegração (ARDL) Bounds Testing Approach to Cointegration. Com a utilização de diferentes formas de agregação para despesas governamentais, os resultados indicam: i) a não validade da Lei de Wagner; ii) a existência de efeitos de Ilusão Fiscal; iii) a presença de uma relação entre receitas e despesas, que é diferente para cada medida das despesas; iv) uma relação positiva entre salário mínimo real e a dinâmica das despesas; e v) uma relação positiva entre o endividamento e as receitas do setor público.

Além desta introdução e das considerações finais, este artigo contém mais 4 seções. A Seção 2 trata dos determinantes da dinâmica dos gastos governamentais, discutindo a Lei de Wagner, a Teoria da Ilusão Fiscal e as diferentes relações possíveis entre receitas e despesas. A seção seguinte realiza uma análise sobre a evolução e a composição das despesas governamentais no Brasil. A quarta seção é dedicada à apresentação da metodologia e dos dados utilizados, ao passo que a quinta seção dedica-se à avaliação dos resultados obtidos.

\section{Determinantes da Dinâmica dos Gastos Governamentais}

A primeira análise da dinâmica temporal das despesas governamentais foi proposta por Adolph Wagner. Seu argumento central é que fatores históricos, 
relacionados às alterações na estrutura econômica e ao processo de desenvolvimento do país, são fundamentais na determinação do nível de gastos do governo, ou seja, existe uma relação entre a elevação dos gastos públicos e o desenvolvimento das economias. Segundo Wagner (1883), o advento da sociedade industrial moderna leva ao aumento da pressão política por "progresso social", isto é, a demanda por ampliação da quantidade de bens e serviços providos pelo setor público aumenta com a industrialização. Isso ocorre devido a três fatores: i) expansão das funções administrativas e de proteção do Estado, por conta do aumento da complexidade das relações jurídicas e de comunicação; ii) necessidade de incremento da oferta de bens e serviços sociais e culturais; iii) necessária intervenção governamental para gerir e financiar monopólios naturais e garantir o bom funcionamento das forças de mercado (Bird 1971).

Essas observações sobre a dinâmica de crescimento dos gastos públicos levam à chamada Lei de Wagner, ou Lei dos Dispêndios Públicos Crescentes, baseada na premissa de uma elevação da renda nacional induzir a um crescimento mais que proporcional das despesas governamentais. Significa que existe uma tendência de longo prazo de ampliação da parcela do produto dedicada às despesas públicas ou, em outras palavras, existe uma elasticidaderenda da demanda por bens e serviços providos pelo Estado maior que a unidade (Bird 1971).

A literatura empírica acerca da Lei de Wagner é extensa. Vários trabalhos observam sua validade para diferentes países e em diferentes períodos. Dentre eles podem ser citados: Courakis et al. (1993), Tobin (2005), Akitoby et al. (2006), Narayan et al. (2008), Karagianni \& Pempetzoglou (2011), Tasseven (2011), Jaén-García (2011), Narayan et al. (2012), Bayrakdar et al. (2015) e Magazzino et al. (2015).

O conceito de Ilusão Fiscal surge no estudo de Puviani (1903), que buscou analisar a capacidade de os governantes manipularem a estrutura fiscal para gerar ilusões que promovam seus projetos políticos. Buchanan (1960) e Buchanan (1967) ampliam o estudo de Puviani (1903) e sugerem que, se o eleitor-contribuinte acredita que os impostos pagos são inferiores ao que realmente são e que os benefícios dos bens e serviços ofertados pelo governo são maiores do que realmente são, ele escolhe sua cesta de gastos e tributos baseado em um conjunto limitado (e/ou falso) de informações. Assim, a Ilusão Fiscal ocorre quando o eleitor-contribuinte não tem clareza de quanto paga para o governo ou de quanto recebe de bens e serviços. Logo, "a percepção sistematicamente errada de parâmetros fiscais chaves pode distorcer significativamente as escolhas fiscais do eleitorado" (Oates (1988), p.65), de modo que os governantes são capazes de criar um viés nas escolhas fiscais do eleitorcontribuinte em determinada direção.

Silva \& Siqueira $(2014)^{1}$ argumentam que a Teoria da Ilusão Fiscal é baseada no entendimento de que é simples para o governo tornar caro para o eleitor-contribuinte obter informação completa a respeito de sua parcela de

\footnotetext{
${ }^{1}$ Silva \& Siqueira (2014) é um dos poucos trabalhos no Brasil, senão o único, que trata empiricamente do caso de Ilusão Fiscal na esfera federal. Os autores encontram indícios de que a Lei de Wagner e a baixa visibilidade da tributação são importantes para explicar o acelerado crescimento das despesas públicas brasileiras entre 1990 e 2011. Apesar de seu caráter pioneiro, o estudo utiliza uma base de dados anuais com somente 22 observações e não leva em conta a dinâmica distinta entre gastos governamentais discricionários e obrigatórios. De fato, esses 2 pontos são justamente onde este presente trabalho tenta avançar.
} 
contribuição para o financiamento do setor público. Como seu voto individualmente não impacta de forma significativa os resultados das decisões públicas, não há incentivos para ele investir seu tempo e seu dinheiro na obtenção dessas informações. Portanto, permanecer mal informado e votar guiado por suas percepções pode ser uma escolha racional (Buchanan \& Wagner 1977). Desse modo, determinadas estruturas fiscais podem induzir o eleitorcontribuinte a subestimar sua contribuição para o financiamento do setor público e, consequentemente, demandar bens e serviços providos pelo Estado em um nível superior ao que desejaria, caso percebesse completamente os custos com o quais está arcando. Além disso, a Ilusão Fiscal facilita a manutenção pelo governo de gastos improdutivos destinados a determinados grupos de interesse, tornando possível que ele acomode as forças que o pressionam por ampliação de gastos. A Ilusão Fiscal, portanto, pode ser importante para explicar o crescimento dos gastos públicos (Tanzi 2011).

Quando a Ilusão Fiscal ocorre pelo superdimensionamento da quantidade ou do benefício de bens e serviços providos pelo governo, há uma ilusão "positiva". Nesse caso, como afirma Tanzi (2011) (p.157), a atuação do governo consiste em fazer com que o eleitor-contribuinte acredite que uma determinada despesa é "realmente capaz de resolver um problema ou fazer uma verdadeira contribuição positiva para o bem-estar público", quando na realidade ela é incapaz de gerar tais benefícios.

Por outro lado, a Ilusão Fiscal é "negativa" quando o eleitor-contribuinte subdimensiona os preços-tributos. Diversas estratégias são utilizadas pelos governos para criar ou explorar a Ilusão Fiscal negativa. Dentre elas, quatro recebem destaque na literatura. Em primeiro lugar, a tributação indireta induz o eleitor-contribuinte a subestimar sua parcela de contribuição para o financiamento do governo, já que parte dos impostos que ele paga permanece encoberta nos preços dos produtos. Como afirma Mill (1996) (p.438), se a arrecadação ocorresse apenas pela cobrança de tributos diretos, a taxação seria muito mais notada e "certamente surgiria uma insatisfação extrema por ter de pagar tanto". Diversos estudos empíricos observam a utilização dessa estratégia pelos gestores. Dentre eles podem ser citados: Gemmell et al. (1999), Sausgruber \& Tyran (2005), Chetty et al. (2009), Dell'anno \& Mourao (2012) e Silva \& Siqueira (2014).

Em segundo lugar, uma maior complexidade ou fragmentação do sistema tributário faz com que o eleitor-contribuinte não perceba com clareza os verdadeiros preços-tributos dos bens e serviços providos pelo Estado, induzindo uma demanda excessivamente alta por gastos públicos. Segundo Buchanan (1967) (p.135), uma vez que "a carga total sobre um indivíduo pode ser fragmentada, de forma que ele confronte inúmeras pequenas taxas em vez de umas poucas significantes, efeitos ilusórios podem ser criados".

Wagner (1976) utiliza a dispersão ${ }^{2}$ da receita tributária entre os diferentes tributos, como medida do grau de complexidade das receitas, e encontra evidências de que a estrutura fiscal pode alterar a percepção que o eleitorcontribuinte possui acerca do preço-tributo. Significa que um sistema tributário mais complexo leva o eleitor-contribuinte a acreditar que paga um menor preço-tributo do que realmente é cobrado pelo governo. Embora haja diversidade de resultados, vários trabalhos empíricos indicam que a ampliação da complexidade fiscal induz um aumento das despesas governamentais. Dentre

\footnotetext{
${ }^{2}$ Essa dispersão foi medida por um índice de concentração de Herfindahl-Hirschman.
} 
eles: Heyndels \& Smolders (1995), Dollery \& Worthington (1995a) Turnbull (1998), Bastiaens et al. (2001) e Dell'anno \& Mourao (2012).

Em terceiro lugar, um sistema de financiamento de gastos do governo por emissão de dívida cria no eleitor-contribuinte a ilusão de ser mais rico. Como afirma Ricardo (1996) (p.179), o financiamento por dívida é "um sistema que tende a tornar-nos menos poupadores e a cegar-nos sobre a nossa real situação". O financiamento via endividamento gera, como obrigação no presente, somente o pagamento de juros da dívida, de forma que eleitor-contribuinte poupa menos para arcar com os custos do gasto público e, consequentemente, tem distorcida sua percepção das despesas reais com bens e serviços ofertados pelo governo.

Segundo Oates (1988), como o eleitor-contribuinte é mais propenso a compreender os custos do financiamento do setor público que se realiza pela arrecadação de tributos, a diluição dos custos ao longo do tempo no passivo fiscal prejudica a percepção do eleitor-contribuinte do que ele paga de preçostributos. Portanto, como indicam Buchanan \& Wagner (1977), déficits públicos elevados levam a geração corrente de eleitores-contribuintes a subestimar o preço-tributo de bens e serviços providos pelo setor público, resultando em maior demanda por gastos e níveis mais elevados de despesas públicas. Diversos estudos empíricos encontram efeitos de ilusão de dívida. Dentre eles podem ser citados: Dollery \& Worthington (1995a), Dollery \& Worthington (1995b), Gemmell et al. (1999), Christopoulos \& Tsionas (2003), Dell'anno \& Mourao (2012) e Banzhaf \& Oates (2012).

A última das principais estratégias utilizadas pelos governos para explorar a Ilusão Fiscal é relacionada ao efeito flypaper. O financiamento do gasto público do governo local por transferências de outras esferas de governo induz o eleitor-contribuinte a acreditar que paga um preço-tributo menor pelos bens e serviços ofertados pelo governo e, consequentemente, a demandar gastos excessivos (Dollery \& Worthington 1996). Embora haja controvérsia na literatura a respeito do efeito flypaper, vários trabalhos empíricos recentes, inclusive no Brasil, atestam a existência do fenômeno. Dentre eles: Dollery \& Worthington (1995a), Dollery \& Worthington (1995b), Dollery \& Worthington (1999), Turnbull (1998), Mendes (2005), Mattos \& Rocha (2011), Sakurai (2013) e Araújo \& Siqueira (2016).

Por fim, na década de 1930 a relação de causalidade entre receitas e despesas do governo já era debatida nos Estados Unidos. Muitos políticos defendiam que a maneira mais efetiva para o controle dos gastos governamentais era a redução de impostos. Essa estratégia é conhecida como "starve the beast", pois apregoa que se deve deixar a fera (governo) passar fome para que ela promova cortes de gastos públicos.

Friedman (1978) reforça esse ponto de vista ao indicar que o governo deseja e irá gastar os recursos que estiverem disponíveis, isto é, que há uma relação causal positiva entre receitas e despesas governamentais: a ampliação (redução) das receitas do governo levará a uma elevação (diminuição) de seus gastos. Essa é a primeira de quatro hipóteses alternativas apresentadas pela literatura para descrever a forma como os processos de arrecadação e dispêndio do governo são relacionados e é conhecida como "arrecadar e gastar" (tax-spend). A partir dela, conclui-se que cortes permanentes de impostos, que não estejam compensando cortes de gastos (uma política starve the beast), é a medida mais eficaz para conter a expansão dos gastos governamentais.

Por outro lado, existe o argumento de que a relação tax-spend é negativa 
(inversa) devido à presença de Ilusão Fiscal (Wagner 1976, Buchanan \& Wagner 1977). Segundo, Buchanan \& Wagner (1977), um corte em impostos não leva necessariamente a uma redução dos gastos, visto que outros mecanismos fiscais podem ser utilizados para garantir a manutenção do nível das despesas públicas, tais como o imposto inflacionário e o endividamento. Dessa forma, torna-se distorcida a percepção que o eleitor-contribuinte tem da realidade, de modo que tende a subestimar a carga tributária que recai sobre ele, isto é, tende a subdimensionar os verdadeiros preços-tributos dos bens e serviços ofertados pelo governo, o que induz níveis excessivamente altos de demanda por gastos públicos. Portanto, uma redução dos impostos gera uma alteração na percepção dos preços-impostos e leva a uma ampliação das despesas do governo.

A segunda hipótese é de um nexo causal do tipo "gastar e arrecadar" (spendtax), isto é, os governos gastam primeiramente e, em seguida, buscam ampliar suas receitas fiscais para financiar suas despesas. Peacock \& Wiseman (1961) e Peacock \& Wiseman (1979) declaram que elevações temporárias nas despesas criadas por alguns eventos especiais, como situações de crise e guerras, levam a elevações de impostos que, posteriormente, tornam-se permanentes. Já de acordo com o modelo de determinação do endividamento público proposto por Barro (1974) e Barro (1979), os gastos financiados por intermédio de emissão de dívida, em última análise, levam a uma ampliação da arrecadação, visto que o endividamento do governo resulta em passivos futuros, que terão como resposta um aumento da tributação em algum momento. Qualquer elevação nos gastos resulta em uma posterior ampliação da carga tributária, de modo que o financiamento de gastos públicos, via emissão de dívida, tem efeitos sobre a demanda e a taxa de juros idênticos aos de um financiamento via impostos, devido aos impactos sobre a poupança presente dos consumidores em resposta a futuras ampliações de impostos. Logo, o governo é indiferente em financiar seus gastos por meio de impostos ou de endividamento, de forma que a solução desejada para a redução dos déficits orçamentários é diminuir os gastos públicos.

Por outro lado, a presença de Ilusão Fiscal levaria a uma relação positiva entre despesas e dívida, conforme explicado anteriormente: a diluição dos custos dos bens e serviços providos pelo governo, por longos períodos, distorce a percepção que o eleitor-contribuinte possui acerca do preço pago e da quantidade consumida de bens e serviços. Assim, o financiamento via ampliação do endividamento induz os contribuintes a uma subestimação das obrigações fiscais correspondentes, tornando-os menos resistentes à expansão do gasto público.

Já a hipótese de "sincronização fiscal" (Meltzer \& Richard 1981, Musgrave 1966) argumenta que decisões sobre despesas e receitas governamentais são tomadas simultaneamente. Como um agente racional, o governo iguala o custo marginal de tributação com o benefício marginal de seus gastos, gerando uma causalidade bidirecional entre arrecadação e gastos públicos.

A última é a hipótese de "neutralidade fiscal", proposta por Baghestani \& Mcnown (1994), que sugere a separação institucional entre as decisões de arrecadação e dispêndio do governo. Significa que as decisões são tomadas de forma independente entre si: as despesas são definidas baseadas nas necessidades expressas pela população e a receita depende da carga tributária máxima tolerada pelos eleitores-contribuintes. Como resultado, o equilíbrio fiscal seria alcançado apenas por coincidência. 
Payne (2003) realiza ampla revisão dos trabalhos que, entre 1980 e 2002, analisam empiricamente a relação de causalidade entre arrecadação e gastos do governo. A maioria dos trabalhos dá suporte à hipótese tax-spend. Porém, devido aos tipos de metodologia utilizados, há poucas evidências acerca da forma da relação, se é direta, como proposta por Friedman (1978), ou inversa, por causa da existência de Ilusão Fiscal.

A literatura empírica internacional posterior ao estudo de Payne (2003) é extensa. Entre os trabalhos mais recentes, merecem destaque Narayan (2005), Narayan \& Narayan (2006), Wolde-Rufael (2008) e Owoye \& Onafowora (2011) que, conjuntamente, testam as diferentes hipóteses de nexo causal entre receitas e despesas para mais de 50 países com diferentes graus de desenvolvimento. Para o caso brasileiro, alguns estudos recentes abordam o assunto, direta ou indiretamente, mas com resultados divergentes. Dentre eles: Cheng (1999), Mattos \& Rocha (2001), Mello (2008), Silva et al. (2010), Gadelha (2011), Bertussi \& Triches (2012) e Araújo (2014). Uma das possíveis explicações para a pluralidade de resultados é o fato de os trabalhos não considerarem a provável diferença entre a dinâmica das despesas determinadas por regras e vinculações orçamentárias da dinâmica dos gastos discricionários. Logo, as estimações com dados desagregados do presente estudo permitem uma reflexão sobre a razão da diversidade de resultados na literatura brasileira acerca da relação receitas-despesas.

\section{Rigidez Orçamentária e Análise com Despesas Desagregadas}

A evolução das despesas e receitas primárias do governo central entre o primeiro trimestre de 1997 e o último trimestre de 2015 é apresentada na Figura $1^{3}$. Nela é perceptível a estreita sincronia entre as duas séries e uma tendência acentuada de expansão dos gastos primários, com destaque para três períodos. O primeiro refere-se ao início do ano de 2003, quando o governo realizou um ajuste fiscal, como pode ser observado pela considerável queda de gastos no primeiro trimestre daquele ano. O segundo é o período mais acentuado da crise de 2008, em que há forte declínio das receitas e a manutenção da elevação dos gastos, como parte de uma política contracíclica. O último refere-se à crise fiscal iniciada no primeiro trimestre de 2014.

O crescimento das receitas, que já havia reduzido seu ritmo a partir de 2012 com a política de benefícios fiscais para setores específicos da economia, colapsa no início de 2014 com a desaceleração da economia. Já as despesas, que mantinham crescimento acelerado, passam a cair a partir do último trimestre de 2014, como parte de uma estratégia de ajuste fiscal. Entretanto, há um forte salto no quarto trimestre de 2015 por causa das operações de reordenamento de passivos.

Uma análise adequada das finanças do governo central no Brasil não pode ser baseada apenas em valores agregados, uma vez que a maior parte dos gastos primários possui grande rigidez e, desse modo, existem diferentes efeitos

\footnotetext{
${ }^{3}$ Os dados apresentados nesta seção são referentes às receitas e despesas primárias líquidas do governo central a valores de junho de 2017 (deflacionadas pelo IPCA) e dessazonalizadas pelo método Census X-12. Foram excluídos das séries os choques causados pela política de concessão da exploração de petróleo: uma receita de $\mathrm{R} \$ 115,63$ bilhões referente à conta de "Cessão Onerosa Exploração Petróleo" e uma despesa de R\$66,35 bilhões referente à realização de uma capitalização da Petrobrás, no terceiro trimestre de 2010; e uma receita de $\mathrm{R} \$ 19,19$ bilhões referente ao bônus recebido pela assinatura do Campo de Libra, no último trimestre de 2013.
} 


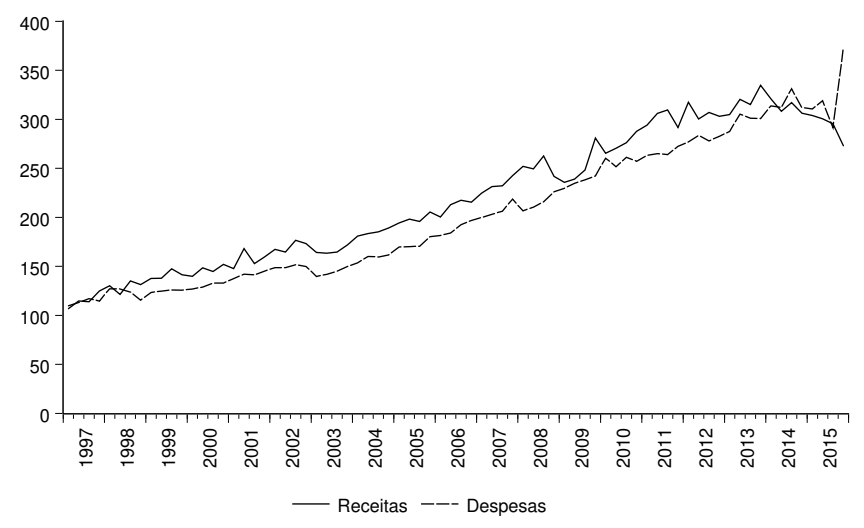

Fonte: Secretaria do Tesouro Nacional

Figura 1: Evolução das Despesas e Receitas Primárias do Governo Central (R\$ bi)

relacionados com as despesas vinculadas e as despesas discricionárias. Há diversas formas de classificar os gastos do governo central: pelo grupo da natureza das despesas, pelo ministério que realiza o dispêndio, pela função, pela subfunção, e assim por diante. Como indica a Tabela 1, as despesas primárias classificadas por função indicam que assistência e previdência social, saúde, educação e trabalho (funções consideradas tipicamente sociais) representam mais de $73 \%$ do total gasto a cada ano.

Tabela 1: Participação das Despesas do Governo Central em 2015

\begin{tabular}{lrlr}
\hline \multicolumn{2}{c}{ Despesas por Função } & \multicolumn{2}{c}{ Despesas por Natureza do Dispêndio } \\
Função & Participação & Natureza & \begin{tabular}{c} 
Participação \\
\hline Assistência Social
\end{tabular} \\
Previdência Social & $6,23 \%$ & Benefícios Assistenciais & $3,72 \%$ \\
Saúde & $44,70 \%$ & Despesas do Banco Central & $0,33 \%$ \\
Trabalho & $8,66 \%$ & Outras Despesas Custeio e Capital & $28,00 \%$ \\
Educação & $5,83 \%$ & Despesa do FAT & $4,18 \%$ \\
Demais Despesas & $7,74 \%$ & Pessoal e Encargos Sociais & $20,56 \%$ \\
& $26,84 \%$ & Benefícios Previdenciários & $37,99 \%$ \\
& & Subsídios e Subvenções Econômicas & $5,02 \%$ \\
& & Transferências ao Banco Central & $0,21 \%$ \\
\hline Todas as Despesas & $100 \%$ & Todas as Despesas & $100 \%$ \\
\hline Fonte: Elaboração própria a partir dos dados do SIAFI
\end{tabular}

Os gastos com programas de transferência de renda e com previdência são determinados por regras estabelecidas na legislação e pelo patamar do salário mínimo. Além disso, o critério de elegibilidade de diversos programas é relacionado também ao salário mínimo, de modo que uma elevação salarial afeta o critério de participação em alguns programas, além de ampliar o valor do abono salarial e o piso da previdência social e do seguro desemprego. Como o salário mínimo é reajustado anualmente pela inflação do ano antecedente e pelo crescimento do PIB de dois anos antes, a elevação da inflação e a aceleração do crescimento econômico levam a variações de tais dispêndios, independente da vontade do policymaker. 
As despesas com saúde e educação também possuem regras de vinculação. Os gastos com saúde, no período analisado, eram determinadas pelo artigo 198 da Constituição Federal de 1988, que estabelecia que os recursos mínimos destinados à saúde fossem definidos por lei complementar reavaliada pelo menos a cada cinco anos. Até 2015, a regra vigente determinava que o dispêndio com saúde aumentasse de acordo com o crescimento do PIB nominal, conforme as disposições da Lei Complementar $n^{\circ} 141 / 2012$. Para 2016, a Emenda Constitucional $n^{\circ} 86 / 2015$ definiu gasto mínimo de $13,2 \%$ da receita corrente líquida. Já os gastos com educação, durante o período examinado, eram estipulados pelo artigo 212 da Constituição Federal, que determinava aplicação de pelo menos $18 \%$ da receita de impostos (descontadas as transferências) na manutenção e desenvolvimento do ensino ${ }^{4}$.

Portanto, uma fração elevada das despesas primárias do governo central não pode ser alterada diretamente conforme a vontade do gestor. O crescimento econômico, a aceleração da inflação e/ou a elevação das receitas impõem uma ampliação de despesas primárias, isto é, a estrutura de vinculações e obrigações de gastos gera uma dinâmica de variação "automática" do dispêndio público. A exceção são os gastos aqui denominados de "Demais Despesas", caracterizados como aqueles que podem ser diretamente comandados pela vontade do gestor, isto é, aqueles anteriormente chamados de discricionários.

Entre as principais despesas primárias divididas pelo grupo da natureza do dispêndio estão presentes os gastos com Benefícios Previdenciários e Benefícios Assistenciais e as Despesas do FAT (Fundo de Amparo ao Trabalhador), todos determinados por regras estabelecidas na legislação e pelo patamar do salário mínimo. Também os gastos com Pessoal e Encargos Sociais possuem dinâmica própria, visto que a maior parte do funcionalismo é concursada e possui estabilidade. Assim, resta apenas o controle sobre a quantidade de funcionários contratados e a abertura de novos concursos, além da possibilidade de negociações coletivas que possibilitem menor ritmo de crescimento salarial.

As "Outras Despesas de Custeio e Capital” são aquelas que possuem dinâmica mais sujeita à intervenção do gestor. Nessa rubrica ficam concentrados os principais gastos discricionários do governo central e a estes correspondem a maior parcela de seu valor total. Evidentemente, também nesse grupo existem despesas sobre as quais não há controle direto.

Os dados apresentados anteriormente indicam a importância de uma análise desagregada das despesas públicas, uma vez que é essencial desagregar a dinâmica autônoma dos gastos vinculados da dinâmica das despesas discricionárias do governo. Uma desagregação é apresentada na Figura 2, na qual os gastos primários do governo central são divididos em Despesas Obrigatórias Benefícios Previdenciários, Pessoal e Encargos Sociais e Outras Despesas Obrigatórias - e em Despesas Discricionárias. A dinâmica geral dos gastos parece ser capturada por tal divisão dos dados, já que ela é capaz de revelar a tendência de forte crescimento dos gastos obrigatórios ao longo de todo período e a queda dos gastos discricionários em 2003, sua expansão acelerada a partir de 2009 e seu recuo no fim de 2014.

\footnotetext{
${ }^{4}$ A partir de 2017, os gastos mínimos com saúde e com manutenção e desenvolvimento do ensino são definidos pela Emenda Constitucional n 95/2016. Além disso, ela estabelece, para cada ano, um limite máximo para o total das despesas primárias do governo central.
} 


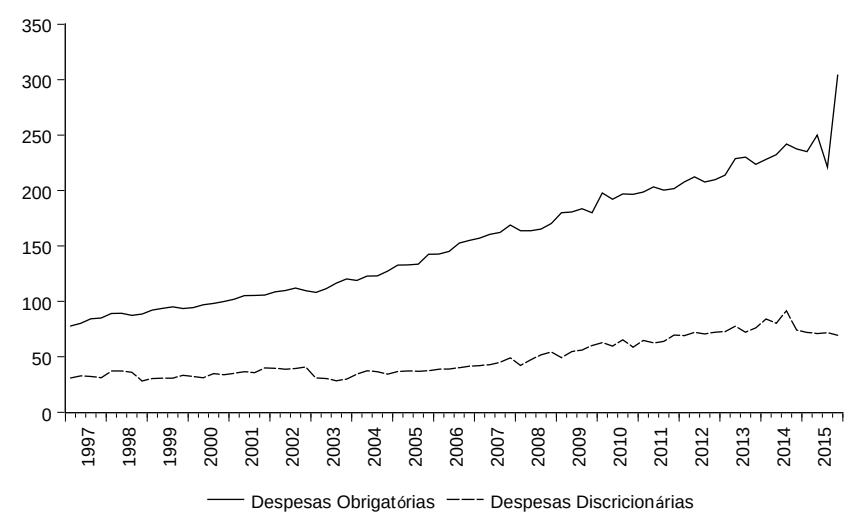

Fonte: Secretaria do Tesouro Nacional

Figura 2: Evolução das Principais Despesas por Natureza do Dispêndio (R\$ bi)

\section{Metodologia Econométrica e Dados}

Para verificar os determinantes da dinâmica das despesas do governo brasileiro, o estudo utilizará a metodologia dos Modelos Autorregressivos de Defasagens Distribuídas (ARDL) aplicados ao arcabouço da cointegração (ARDL) Bounds Testing Approach to Cointegration, propostos nos trabalhos de Pesaran \& Shin (1998) e Pesaran et al. (2001). Essa metodologia foi utilizada por permitir: i) usar um conjunto de variáveis com um nível ótimo de defasagens para cada uma delas, determinado por um critério de seleção previamente escolhido; ii) determinar a relação de cointegração em amostras pequenas; e iii) empregar um conjunto de variáveis com diferentes ordens de integração.

É possível representar um modelo $\operatorname{ARDL}\left(p, q_{1}, \ldots, q_{j}\right)$ geral como:

$$
y_{t}=\alpha_{0}+\alpha_{1} t+\sum_{i=1}^{p} \gamma_{i} y_{t-i}+\sum_{j=1}^{k} \sum_{i=0}^{q_{j}} \beta_{j, i} x_{j, t-i}+u_{t}
$$

em que $\alpha_{0}$ e $\alpha_{1}$ são os coeficientes de intercepto e tendência $(t) ; x_{j, t}$ são variáveis $I(1)$ que não são cointegradas entre si; e $u_{t}$ são os distúrbios serialmente não correlacionados com média zero e variância constante.

Para confirmar a existência de vetores de cointegração e obter os coeficientes de curto e longo prazo, o modelo é estimado na forma de correção de erros (ARDL-ECM), que pode ser especificada a partir da primeira diferença da Equação (1):

$$
\begin{aligned}
\Delta y_{t}=\alpha_{0} & +\sum_{i=1}^{p-1} \phi_{1, i} \Delta y_{t-i}+\sum_{j=1}^{k} \sum_{i=0}^{q_{j}-1} \phi_{2, i} \Delta x_{j, t-i} \\
& +\psi y_{t-1}-\alpha_{1}(t-1)-\sum_{j=1}^{k} \delta_{j} x_{j, t-1}+\varepsilon_{t}
\end{aligned}
$$

em que $\alpha_{0}$ é o coeficiente de intercepto; $x_{j, t}$ são variáveis $I(1)$ que não são cointegradas entre si; $\phi_{1, i}$ e $\phi_{2, i}$ são os coeficientes de curto prazo; $\psi$ é coeficiente 
de correção de erros; $\frac{\alpha_{1}}{\psi}$ é o coeficiente de tendência de longo prazo; $\frac{\delta_{j}}{\psi}$ são os coeficientes de longo prazo; e $\varepsilon_{t}$ são os distúrbios tipo ruído branco.

Pesaran et al. (2001) desenvolveram um teste que permite verificar a existência de uma relação entre uma variável dependente e um conjunto de regressores, quando não se sabe se as variáveis explicativas são estacionárias. Os testes propostos são baseados em um teste de Wald elaborado para verificar a significância dos níveis defasados das variáveis em um mecanismo de correção de equilíbrio univariado. Como essas estatísticas sob a hipótese nula não possuem distribuição assintótica padrão independentemente da ordem de integração das variáveis explicativas, dois conjuntos de valores críticos assintóticos são calculados: um no qual todos os regressores são puramente $I(1)$ e o outro no qual todos são puramente $I(0)$. Por essa razão, a abordagem é chamada de bounds testing, isto é, os dois conjuntos de valores críticos fornecem as bandas que abrangem todas as classificações possíveis dos regressores para puramente $I(0)$, puramente $I(1)$ ou mutuamente cointegradas.

O procedimento de teste ocorre realizando-se a comparação entre a estatística de teste, cuja hipótese nula é de inexistência de vetores de cointegração, $H_{0}: \psi=\alpha_{1}=\delta_{1}=\delta_{2}=\ldots=\delta_{k}=0$, e os valores das bandas pré-estabelecidas. Se a estatística de teste for menor que o valor crítico da banda inferior, a hipótese nula não é rejeitada, enquanto se a mesma for maior que o valor crítico da banda superior, a hipótese nula é rejeitada. Por último, no caso em que a estatística de teste fica dentro do intervalo estabelecido pelas bandas, é necessário conhecer a ordem de integração das variáveis.

O período analisado neste trabalho vai do primeiro trimestre de 1997 ao último de 2013. As séries utilizadas estão em números-índices (1997T1=100) e são as seguintes ${ }^{5}$ :

- Receitas Primárias $(R)$ : Série calculada a partir dos dados de Resultado do Tesouro disponibilizados pela Secretaria do Tesouro Nacional (STN) para o total de receitas primárias líquidas do governo central. Valores deflacionados, tornados trimestrais e dessazonalizados.

- Despesas Primárias $(G)$ : Série calculada a partir dos dados da STN para o total de despesas primárias líquidas do governo central. Valores deflacionados, tornados trimestrais e dessazonalizados.

- Despesas Obrigatórias (GO): Série calculada a partir dos dados da STN para as despesas primárias líquidas desagregadas pela natureza do gasto. Valores da despesa com Benefícios Previdenciários, Pessoal e Encargos Sociais e Outras Despesas Obrigatórias são deflacionados e tornados trimestrais. Em seguida, são somadas e dessazonalizadas.

- Despesas Discricionárias (GD): Dados disponibilizados pela STN na desagregação pela natureza do gasto. Valores deflacionados, tornados trimestrais e dessazonalizados.

- PIB (Y): Série calculada via deflacionamento e dessazonalização dos dados trimestrais disponibilizados pelo Instituto Brasileiro de Geografia e Estatística (IBGE) para o Produto Interno Bruto (PIB).

\footnotetext{
${ }^{5}$ As variáveis são deflacionadas utilizando o Índice de Preços ao Consumidor Amplo (IPCA) e estão em valores para junho de 2017. Para a dessazonalização foi utilizado o método Census $\mathrm{X}-12$.
} 
- Salário $(W)$ : Série calculada via dessazonalização da média do trimestre do salário mínimo mensal deflacionado.

- Dívida $(D I V)$ : Série calculada via dessazonalização da média no trimestre da dívida líquida do governo federal e Banco Central.

- Visibilidade da Receita Tributária (IR): Série calculada via dessazonalização da participação do imposto de renda nas receitas primárias totais. Os valores utilizados para os cálculos são disponibilizados pela STN.

- Dummy (d) para o período 2003T1-2004T4, quando o governo realizou um considerável ajuste fiscal.

A utilização do conceito primário para receitas e despesas do governo central, em vez do conceito nominal, reflete o entendimento de que a inclusão do dispêndio com juros prejudicaria a compreensão da verdadeira relação entre as variáveis nos termos definidos anteriormente, já que esse gasto é afetado pela condução da política monetária. Por outro lado, é importante a inclusão do salário mínimo nas estimações, visto que ele é responsável por uma fração considerável da dinâmica dos gastos públicos, conforme apresentado na Seção 3. Além disso, como a arrecadação e o gasto público são potencialmente sensíveis às alterações do nível de atividade econômica, a inclusão do produto real como variável de controle é importante por possibilitar a diferenciação da causalidade direta entre receitas e despesas da causalidade indireta via PIB. A inclusão da variável referente ao produto permite ainda avaliar a validade da Lei de Wagner.

Já as variáveis utilizadas para identificar o efeito da Ilusão Fiscal foram escolhidas por retratarem a visibilidade da tributação e o endividamento público, duas das principais formas usadas por governos para criar ou explorar a Ilusão Fiscal. Vale ressaltar que a opção por testar a hipótese de Mill e não a hipótese da complexidade da receita (utilizando um índice de concentração), também feita por Silva \& Siqueira (2014), se deve às características das séries disponíveis. De fato, os dados para a arrecadação com impostos e taxas são apresentados de maneiras diferentes ao longo dos anos, de modo que utilizá-los requer compatibilizar as classificações. A reclassificação geraria grandes categorias contendo diversos tributos. Cada uma delas seria considerada como um único tributo no cálculo de um índice de concentração, o que pode causar uma desconexão entre seu valor e a real complexidade da receita. Além disso, os dados para a arrecadação via contribuições não possuem disponibilidade compatível com a frequência utilizada no trabalho. Embora seja uma proxy mais simples, a participação do imposto mais visível (imposto de renda) nas receitas primárias não está exposta aos mesmos problemas, sendo mais útil para analisar a presença de Ilusão Fiscal na condução das finanças públicas brasileiras.

A Tabela 2 contém as estatísticas descritivas das variáveis (antes de se tornarem números-índices) para o período em análise. É perceptível o ritmo acelerado de crescimento das receitas e despesas primárias, que partem de $\mathrm{R} \$ 106,756$ bilhões e $\mathrm{R} \$ 109,628$ bilhões, respectivamente, nos trimestres iniciais das séries e alcançam $\mathrm{R} \$ 334,684$ bilhões e $\mathrm{R} \$ 305,235$ bilhões, respectivamente, em 2013. As médias e as medianas indicam que no período a arrecadação primária foi superior aos gastos primários. A Figura 1 mostra que 
esse quadro se reverte fortemente nos trimestres seguintes, que não foram incluídos na análise desta seção. Por outro lado, verifica-se que o crescimento econômico no período foi consistentemente menor que o crescimento das receitas e despesas $(G, G O$ e $G D)$. Além disso, a dívida mais que triplicou no período, passando de $\mathrm{R} \$ 447,136$ bilhões no primeiro trimestre de 1997 para $\mathrm{R} \$ 1.528,987$ bilhões no segundo trimestre de 2011, apesar de o dispêndio primário do governo central ter sido em média menor que sua arrecadação primária. Já a participação do imposto de renda nas receitas primárias flutua ao longo do período, atingindo a mínima de $21,52 \%$ no terceiro trimestre de 2010 e alcançando a máxima de 31,30\% no terceiro trimestre de 2008.

Tabela 2: Estatísticas Descritivas

\begin{tabular}{lrrrrr}
\hline \multicolumn{1}{c}{ Variáveis } & Média & Mediana & Máximo & Mínimo & Desvio Padrão \\
\hline Receitas Primárias (R) & 209,156 & 196,997 & 334,684 & 106,756 & 64,111 \\
Despesas Primárias (G) & 188,650 & 170,210 & 305,235 & 109,628 & 58,969 \\
Despesas Obrigatórias (GO) & 143,316 & 133,206 & 230,071 & 77,779 & 45,222 \\
Despesas Discricionárias (GD) & 45,324 & 39,218 & 77,556 & 28,135 & 14,464 \\
PIB (Y) & $1.159,723$ & $1.053,401$ & $1.748,210$ & 794,080 & 299,804 \\
Salário (W) & 607,991 & 558,043 & 889,578 & 397,477 & 159,473 \\
Dívida (DIV) & $1.192,552$ & $1.265,782$ & $1.528,987$ & 447,136 & 280,288 \\
Visibilidade da Receita Tributária & 0,276 & 0,277 & 0,313 & 0,215 & 0,020 \\
(IR) & & & & & \\
\hline
\end{tabular}

Os procedimentos econométricos deste trabalho são baseados na estimação de seis modelos ARDL. Os três primeiros analisam os determinantes do processo decisório de dispêndio do governo. O Modelo 1 é especificado, com base na Equação (1), como:

$$
\begin{aligned}
\ln G_{t}=\alpha_{0}+ & \alpha_{1} t+\alpha_{2} d+\sum_{i=1}^{p} \gamma_{i} \ln G_{t-i}+\sum_{i=0}^{q_{1}} \beta_{1, i} \ln R_{t-i}+\sum_{i=0}^{q_{2}} \beta_{2, i} \ln Y_{t-i} \\
& +\sum_{i=0}^{q_{3}} \beta_{3, i} \ln W_{t-i}+\sum_{i=0}^{q_{4}} \beta_{4, i} \ln D I V_{t-i}+\sum_{i=0}^{q_{5}} \beta_{5, i} \ln I R_{t-i}+u_{t}
\end{aligned}
$$

em que, ln é o operador do logaritmo natural; $G_{t}$ são as despesas e $R_{t}$ as receitas primárias líquidas do governo central; $Y_{t}$ é o PIB; e $W_{t}$ é o salário mínimo real; $D I V_{t}$ é a dívida líquida; $I R_{t}$ é a participação do imposto de renda na arrecadação primária; $t$ é um termo de tendência; e $d$ é a dummy para o período 2003T1-2004T4.

Os Modelos 2 e 3 se diferenciam do Modelo 1 por substituírem as despesas primárias $\left(G_{t}\right)$ pelas despesas com dinâmica que independe da vontade do gestor $\left(G O_{t}\right)$ e pelas discricionárias $\left(G D_{t}\right)$, respectivamente. Além disso, no Modelo 3 não é incluída uma tendência $(t)$ na especificação, uma vez que, como discutido anteriormente, as despesas utilizadas não apresentam uma tendência que independa da vontade do gestor.

Já os três modelos seguintes analisam os determinantes do processo decisório de arrecadação do governo. O Modelo 4 é especificado como: 


$$
\begin{aligned}
\ln R_{t}= & \alpha_{0}+\alpha_{1} d+\sum_{i=1}^{p} \gamma_{i} \ln R_{t-i}+\sum_{i=0}^{q_{1}} \beta_{1, i} \ln G_{t-i}+\sum_{i=0}^{q_{2}} \beta_{2, i} \ln Y_{t-i} \\
& +\sum_{i=0}^{q_{3}} \beta_{3, i} \ln W_{t-i}+\sum_{i=0}^{q_{4}} \beta_{4, i} \ln D I V_{t-i}+\sum_{i=0}^{q_{5}} \beta_{5, i} \ln I R_{t-i}+u_{t}
\end{aligned}
$$

Os Modelos 5 e 6 se diferenciam do Modelo 4 por utilizarem as desagregações Despesas Obrigatórias $\left(G O_{t}\right)$ e Despesas Discricionárias $\left(G D_{t}\right)$, respectivamente, como variável que descreve o processo decisório de dispêndio do governo.

Os valores esperados para os coeficientes de longo prazo são relatados na Tabela 3 e têm como referência os trabalhos na área de finanças públicas apresentados na Seção 2, especialmente aqueles informados na coluna de Referencial Teórico.

\begin{tabular}{|c|c|c|c|}
\hline \multicolumn{4}{|c|}{ Especificações para Dispêndio } \\
\hline Variável & Valor & Significado & Referencial Teórico \\
\hline \multirow{5}{*}{$\ln R$} & $>0$ & Tax-spend & Friedman (1978) \\
\hline & $<0$ & Tax-spend inverso & Buchanan \& Wagner (1977) \\
\hline & \multirow{3}{*}{$=0$} & \multirow{3}{*}{$\begin{array}{l}\text { Neutralidade fiscal } \\
\text { Spend-tax } \\
\text { Spend-tax inverso }\end{array}$} & Baghestani \& Mcnown (1994) \\
\hline & & & Peacock \& Wiseman $(1961,1979)$ \\
\hline & & & Buchanan \& Wagner (1977) \\
\hline $\ln Y$ & $>1$ & Lei de Wagner & Wagner (1883) \\
\hline $\ln D I V$ & $>0$ & Ilusão fiscal & Ricardo (1996) \\
\hline $\ln I R$ & $<0$ & Ilusão fiscal & Mill (1996) \\
\hline \multicolumn{4}{|c|}{ Especificações para Arrecadação } \\
\hline Variável & Valor & Significado & Referencial Teórico \\
\hline \multirow{2}{*}{$\ln G$} & \multirow{2}{*}{$>0$} & Spend-tax & Peacock \& Wiseman $(1961,1979)$ \\
\hline & & Sincronização fiscal & Meltzer \& Richard (1981) \\
\hline $\ln G O$ & $<0$ & Spend-tax inverso & Buchanan \& Wagner (1977) \\
\hline \multirow{3}{*}{$\ln G D$} & \multirow{3}{*}{$=0$} & Neutralidade fiscal & Baghestani \& Mcnown (1994) \\
\hline & & Tax-spend & Friedman (1978) \\
\hline & & Tax-spend inverso & Buchanan \& Wagner (1977) \\
\hline
\end{tabular}

Tabela 3: Modelos ARDL: Valores Esperados

\section{Resultados}

O primeiro passo da análise é selecionar os melhores modelos pelo Critério de Akaike (AIC) para até 4 defasagens. A Tabela 4 reporta as defasagens selecionadas dos Modelos 1 a 6, assim como os resultados dos testes de diagnósticos, que indicam ausência de heteroscedasticidade e correlação serial para todos os modelos.

A inclusão de uma proxy para renda nacional pode levar à existência de mais de um vetor de cointegração, uma vez que choques fiscais poderiam impactar sobre o produto. Uma inferência eficiente sobre os parâmetros de cointegração na presente modelagem com equações individuais pode ser realizada caso a variável seja exogenamente fraca (Engle et al. 1983, Johansen 
Tabela 4: Modelos ARDL: Defasagens e Testes de Diagnóstico

\begin{tabular}{lccc}
\hline Especificação & Defasagens & Heterocedasticidade & Autocorrelação \\
\hline Modelo 1 & $(3,4,2,4,4,4)$ & 0,9256 & 1,8754 \\
& & {$[0,5793]$} & {$[0,1693]$} \\
Modelo 2 & $(4,0,3,4,0,3)$ & 0,6369 & 0,2143 \\
& & {$[0,8662]$} & {$[0,8080]$} \\
Modelo 3 & $(1,0,0,0,0,0)$ & 1,6579 & 0,2822 \\
& & {$[0,1373]$} & {$[0,7552]$} \\
Modelo 4 & $(3,0,3,1,3,4)$ & 0,3896 & 0,0475 \\
& & {$[0,9872]$} & {$[0,9537]$} \\
Modelo 5 & $(1,2,3,1,0,4)$ & 0,6197 & 0,6912 \\
\multirow{2}{*}{ Modelo 6 } & $(1,4,2,1,3,4)$ & {$[0,8586]$} & {$[0,5063]$} \\
& & 0,3045 & 0,5760 \\
& & {$[0,9976]$} & {$[0,5668]$} \\
\hline
\end{tabular}

Nota: $\mathrm{p}$-valores apresentados entre colchetes

1992, 1995, Urbain 1992). Os resultados dos testes de exogeneidade, apresentados na Tabela 5, indicam que a hipótese nula de exogeneidade fraca não pode ser rejeitada.

Os testes de estabilidade de Soma Cumulativa Recursiva dos Resíduos (CUSUM) e Soma Cumulativa Recursiva dos Resíduos ao Quadrado (CUSUMQ), sugeridos por Brown et al. $(1975)^{6}$, indicam que os valores dos testes para todos os modelos estão entre as bandas de valores críticos, calculadas ao nível de significância estatística de 5\%. Logo, a hipótese nula de estabilidade dos coeficientes não pode ser rejeitada.

Tabela 5: Modelos ARDL: Valores Esperados

\begin{tabular}{lccc}
\hline \multirow{2}{*}{ Especificação } & \multirow{2}{*}{ Exogeneidade } & \multicolumn{2}{c}{ Estabilidade } \\
& & CUSUM & CUSUMQ \\
\hline Modelo 1 & 0,2296 & Estável & Estável \\
& {$[0,6318]$} & & \\
Modelo 2 & 1,4905 & Estável & Estável \\
& {$[0,2221]$} & & \\
Modelo 3 & 0,1396 & Estável & Estável \\
& {$[0,7087]$} & & \\
Modelo 4 & 0,0118 & Estável & Estável \\
& {$[0,9134]$} & & \\
Modelo 5 & 1,2454 & Estável & Estável \\
& {$[0,2644]$} & Estável & Estável \\
Modelo 6 & 0,1396 & & \\
& {$[0,7087]$} & & \\
\hline
\end{tabular}

Nota: p-valores apresentados entre colchetes

Após definir as defasagens do modelo, é necessário verificar a existência de vetores de cointegração entre as variáveis (Tabela 6). A hipótese nula de ausência de vetores de cointegração pode ser rejeitada ao nível de significância estatística de $5 \%$ em cinco dos seis modelos, já que os valores das estatísticas $F$ são maiores que a banda superior. A exceção é o Modelo 4, cujo resultado é inconclusivo, visto que a estatística de teste ficou entre as duas bandas. Contudo, a ausência de cointegração pode ser rejeitada a $10 \%$, uma vez que as bandas a esse nível de significância são 2,08-3,00. Além disso, o modelo especifica o impacto das despesas primárias sobre as receitas primárias, de modo que a indefinição a respeito da existência de cointegração confirma a necessidade de utilizar modelos desagregados, como os propostos no estudo.

\footnotetext{
${ }^{6}$ Os gráficos que contêm os resultados dos testes de estabilidade não são reportados, mas
} 
Tabela 6: Modelos ARDL: Testes de Cointegração (Bounds Testing)

\begin{tabular}{lcc}
\hline Especificação & Estatística F & Valores Críticos \\
\hline Modelo 1 & 8,791 & $2,81-3,76$ \\
Modelo 2 & 3,831 & $2,81-3,76$ \\
Modelo 3 & 5,015 & $2,39-3,38$ \\
Modelo 4 & 3,288 & $2,39-3,38$ \\
Modelo 5 & 16,932 & $2,39-3,38$ \\
Modelo 6 & 11,427 & $2,39-3,38$ \\
\hline Nota: Valores críticos tabulados por Pesaran et al. \\
(2001)
\end{tabular}

\subsection{Estimações de Longo Prazo}

Confirmada a existência de cointegração entre as variáveis dos modelos, são estimados os coeficientes das relações de longo prazo (Tabela 7). No Modelo 1 , o coeficiente referente ao produto $(\ln Y)$ é positivo e significante a $5 \%$, porém seu valor de 0,470 indica que uma elevação percentual da produção induz um aumento de gastos inferior a $1 \%$, de forma que as despesas crescem menos que proporcionalmente com a elevação do produto. Isso leva a indícios contra a validade da Lei de Wagner.

Tabela 7: Modelos ARDL: Coeficientes de Longo Prazo

\begin{tabular}{|c|c|c|c|c|c|c|}
\hline Regressor & Modelo 1 & Modelo 2 & Modelo 3 & Modelo 4 & Modelo 5 & Modelo 6 \\
\hline $\ln R$ & $\begin{array}{l}-0,664 \\
{[0,0167]}\end{array}$ & $\begin{array}{r}0,060 \\
{[0,7056]}\end{array}$ & $\begin{array}{r}0,306 \\
{[0,6032]}\end{array}$ & & & \\
\hline $\ln G$ & & & & $\begin{array}{c}0,251 \\
{[0,3241]}\end{array}$ & & \\
\hline $\operatorname{lngO}$ & & & & & $\begin{array}{r}0,566 \\
{[0,0001]}\end{array}$ & \\
\hline $\operatorname{lnGD}$ & & & & & & $\begin{array}{l}-0,173 \\
{[0,0026]}\end{array}$ \\
\hline $\ln Y$ & $\begin{array}{r}0,470 \\
{[0,0104]}\end{array}$ & $\begin{array}{l}-0,942 \\
{[0,0288]}\end{array}$ & $\begin{array}{r}1,023 \\
{[0,1302]}\end{array}$ & $\begin{array}{r}0,637 \\
{[0,0023]}\end{array}$ & $\begin{array}{r}0,535 \\
{[0,0000]}\end{array}$ & $\begin{array}{r}1,044 \\
{[0,0000]}\end{array}$ \\
\hline $\ln W$ & $\begin{array}{r}0,787 \\
{[0,0000]}\end{array}$ & $\begin{array}{r}1,227 \\
{[0,0002]}\end{array}$ & $\begin{array}{l}-0,110 \\
{[0,8193]}\end{array}$ & $\begin{array}{r}0,097 \\
{[0,7347]}\end{array}$ & $\begin{array}{l}-0,169 \\
{[0,2952]}\end{array}$ & $\begin{array}{r}0,195 \\
{[0,0936]}\end{array}$ \\
\hline $\operatorname{lnDIV}$ & $\begin{array}{r}0,073 \\
{[0,1207]}\end{array}$ & $\begin{array}{l}-0,119 \\
{[0,1258]}\end{array}$ & $\begin{array}{l}-0,168 \\
{[0,3033]}\end{array}$ & $\begin{array}{r}0,254 \\
{[0,0000]}\end{array}$ & $\begin{array}{r}0,177 \\
{[0,0000]}\end{array}$ & $\begin{array}{r}0,232 \\
{[0,0000]}\end{array}$ \\
\hline $\operatorname{lnIR}$ & $\begin{array}{c}-0,086 \\
{[0,3040]}\end{array}$ & $\begin{array}{c}-0,364 \\
{[0,0239]}\end{array}$ & $\begin{array}{c}-0,377 \\
{[0,2140]}\end{array}$ & $\begin{array}{c}-0,208 \\
{[0,2872]}\end{array}$ & $\begin{array}{c}-0,019 \\
{[0,8266]}\end{array}$ & $\begin{array}{l}-0,080 \\
{[0,3617]}\end{array}$ \\
\hline $\mathrm{T}$ & $\begin{array}{r}0,009 \\
{[0,0013]}\end{array}$ & $\begin{array}{r}0,012 \\
{[0,0012]}\end{array}$ & & & & \\
\hline $\mathrm{C}$ & & & $\begin{array}{r}1,614 \\
{[0,3509]}\end{array}$ & $\begin{array}{l}-0,109 \\
{[0,8963]}\end{array}$ & $\begin{array}{l}-0,390 \\
{[0,3220]}\end{array}$ & $\begin{array}{l}-0,966 \\
{[0,0245]}\end{array}$ \\
\hline
\end{tabular}

Notas: p-valores dos testes de significância estatística apresentados entre colchetes

${ }^{*},{ }^{* *} \mathrm{e}^{* * *}$ indicam significância estatística a $10 \%, 5 \%$ e $1 \%$, respectivamente.

O parâmetro estimado para o salário mínimo real $(\ln W)$ é significante mesmo a $1 \%$, indicando que um aumento salarial de $1 \%$ leva a uma expansão de aproximadamente $0,787 \%$ das despesas primárias. A insignificância estatística (p-valores de 0,3040 e 0,1207, respectivamente) dos coeficientes para a visibilidade da tributação $(\ln I R)$ e endividamente público $(\ln D I V)$ indica

estão disponíveis, caso necessário. 
ausência de Ilusão Fiscal. Por fim, como a estimação do parâmetro referente às receitas primárias $(\ln R)$ é significante a $5 \%$ e negativo $(-0,664)$, há indícios de presença de uma relação tax-spend com Ilusão Fiscal.

Os resultados para o Modelo 2 também indicam que a Lei de Wagner não é válida, dado o sinal negativo do coeficiente para $\ln Y$. Já o parâmetro estimado para o salário mínimo $(\ln W)$ é significante a $1 \%$ e maior que 1 , indicando que os gastos obrigatórios crescem mais que proporcionalmente com aumentos salariais. A presença de Ilusão Fiscal é confirmada pelo valor negativo e significância estatística do coeficiente referente à visibilidade da tributação $(\ln I R)$. Em outras palavras, uma percepção menor do eleitor-contribuinte do quanto ele efetivamente paga ao governo permite uma expansão dos gastos por parte do gestor. Por fim, não se observa uma relação tax-spend dada a falta de significância estatística do parâmetro referente à arrecadação $(\ln R)$.

No Modelo 3 os coeficientes para as diferentes variáveis não são estatisticamente significantes. Esse resultado indica que os gastos discricionários do governo são pouco influenciados pelas variáveis do modelo. Aparentemente, como a maior parte dos gastos primários do governo central possui grande rigidez, as despesas discricionárias refletem especialmente a vontade do gestor no momento, que pode se alterar mesmo que não haja mudanças das condições econômicas especificadas no modelo.

Já os resultados para o Modelo 4 mostram a importância da atividade econômica na arrecadação do governo central. O coeficiente referente ao produto $(\ln Y)$ é 0,637 e possui significância estatística, indicando que um produto real $1 \%$ maior aumenta as receitas primárias em aproximadamente 0,637\%. Não há significância estatística para as despesas primárias $(\ln G)$, corroborando o resultado de tax-spend inverso. Por outro lado, o coeficiente de endividamento $(\ln D I V)$ é significante estatisticamente e indica que uma elevação do endividamento induz um aumento da arrecadação. Esse resultado aponta para uma relação como a descrita por Barro (1974) e Barro (1979): as despesas financiadas por emissão de dívida levam a passivos futuros que serão pagos com ampliação da tributação.

As estimações referentes aos Modelos 5 e $\mathbf{6}$ mostram a importância do crescimento econômico $(\ln Y)$ e do endividamento $(\ln D I V)$ para a ampliação das receitas, dada a significância estatística de ambos coeficientes. Também são significantes os parâmetros estimados para as despesas com dinâmica autônoma (lnGO), cujo valor positivo sinaliza a presença de uma relação spendtax (Modelo 5), e para as despesas discricionárias ( $\ln G D)$, cujo valor negativo indica uma relação spend-tax com Ilusão Fiscal (Modelo 6). Para ambos os modelos, o coeficiente para visibilidade da tributação $(\ln I R)$ não possui significância estatística.

Em suma, os resultados dos modelos com dados agregados não apontam para indícios de Ilusão Fiscal, ao passo que as estimações com gastos desagregados sinalizam a presença de Ilusão Fiscal causada pela baixa visibilidade da tributação. Além disso, a análise dos gastos primários indica uma relação taxspend com Ilusão Fiscal. Porém, quando as desagregações são implementadas, observa-se uma relação spend-tax direta, para as despesas obrigatórias, e uma relação spend-tax inversa (com Ilusão Fiscal), para as despesas discricionárias. Isso significa que aumentos de gastos obrigatórios levam à ampliação da arrecadação. O processo não é percebido com nitidez pelo eleitor-contribuinte, devido à baixa visibilidade da tributação e à estrutura existente de regras e vinculações orçamentárias. Por outro lado, a expansão dos gastos discricioná- 
rios tem percepção mais clara pelo eleitor-contribuinte, que, graças à Ilusão Fiscal, enxerga nesse aumento do dispêndio um excesso de recursos do governo e, por isso, pressiona por redução da arrecadação.

Essas diferenças nos resultados dos modelos revelam que analisar as despesas desconsiderando as distinções institucionais existentes entre os diferentes tipos de gastos levam a conclusões imprecisas sobre o processo de definição das despesas primárias pelo governo central. Portanto, as estimações realizadas utilizando variadas desagregações de gastos permitem compreender a diversidade de resultados presentes na literatura brasileira, composta de trabalhos com dados agregados. Primeiramente, a elasticidade-renda obtida é menor que 1 em todos os modelos, de modo que não há indícios de que a Lei de Wagner seja válida para o Brasil no período, em linha com os resultados obtidos por Silva et al. (2010) e contrastante aos obtidos por Silva \& Siqueira (2014). Já o coeficiente estimado para a visibilidade tributária no modelo com gastos agregados indica ausência de Ilusão Fiscal. Contudo, as estimações com dados agregados escondem a importância do fenômeno na dinâmica das despesas obrigatórias, embora a intensidade do efeito seja razoavelmente inferior $(-0,364$ contra $-1,22)$ ao encontrado por Silva \& Siqueira (2014). Por último, há indícios de uma relação tax-spend inversa entre as despesas e as receitas primárias, como presente no trabalho de Araújo (2014). Todavia, quando os dados são desagregados as relações reveladas são outras: assim como em Mattos \& Rocha (2001) e Mello (2008), há uma relação spend-tax entre despesas obrigatórias e receitas primárias; enquanto que entre despesas discricionárias e receitas primárias há uma relação spend-tax inversa, em linha com o resultado obtido por Silva et al. (2010).

\subsection{Curto Prazo: Mecanismo de Correção de Erros}

Verificados os efeitos no longo prazo, o próximo passo da análise é estimar os modelos na forma de vetores de correção de erros para avaliar como ocorrem os ajustamentos de curto prazo. Os resultados reportados ${ }^{7}$ na Tabela 8 indicam que desvios da trajetória de longo prazo das despesas primárias (Modelo 1) são corrigidos por variações nas receitas, no produto, no salário mínimo, no endividamento público e na visibilidade da tributação. Para o caso do Modelo 2, os desvios da trajetória de longo prazo das despesas com dinâmica autônoma são corrigidos por variações no produto, no salário mínimo e na visibilidade da tributação. Por outro lado, não há evidência de relação de curto prazo entre as despesas discricionárias e as demais variáveis (Modelo 3).

No Modelo 4 os desvios da trajetória de longo prazo das receitas primárias são corrigidos por variações no produto, no salário mínimo, no endividamento público e na visibilidade da tributação. No Modelo 5 eles são corrigidos por variações nas despesas obrigatórias, no produto e na visibilidade da tributação. No Modelo 6 a correção ocorre por variações nos gastos discricionários, no produto, no salário mínimo, no endividamento público e na visibilidade da tributação.

Os coeficientes de ECM dos diferentes modelos são estatisticamente significantes a $1 \%$, confirmando uma relação de longo prazo estável entre as variáveis. Os ECM dos Modelos 2, 3 e 4 (-0,596, -0,492 e -0,710, respectivamente)

\footnotetext{
${ }^{7}$ Apenas o ECM de cada modelo foi reportado. Entretanto, os coeficientes de curto prazo estão disponíveis, caso necessário.
} 
Tabela 8: Modelos

ARDL: Dinâmica de

Curto Prazo

\begin{tabular}{lc}
\hline Especificação & ECM(-1) \\
\hline Modelo 1 & $-1,205$ \\
& {$[0,0000]$} \\
Modelo 2 & $-0,596$ \\
& {$[0,0000]$} \\
Modelo 3 & $-0,492$ \\
& {$[0,0000]$} \\
Modelo 4 & $-0,710$ \\
& {$[0,0000]$} \\
Modelo 5 & $-1,182$ \\
& {$[0,0000]$} \\
Modelo 6 & $-1,158$ \\
& {$[0,0000]$} \\
\hline \multicolumn{2}{l}{ Nota: p-valores entre } \\
colchetes
\end{tabular}

indicam que, aproximadamente, 59,6\%, 49,2\% e 71\% do desvio da trajetória de longo prazo são corrigidos no trimestre subsequente. Já os ECM dos Modelos 1,5 e $6(-1,205,-1,182$ e $-1,158$, respectivamente) indicam que os desvios da trajetória de longo prazo são mais que corrigidos no período seguinte.

\section{Considerações Finais}

O presente trabalho investigou a dinâmica das despesas do governo brasileiro entre 1997-2013. Inicialmente, foram levantadas três abordagens presentes na literatura para explicar a dinâmica dos gastos públicos. A primeira é referente à Lei de Wagner, que indica que com o desenvolvimento econômico há uma ampliação da pressão dos eleitores-contribuintes por progresso social, ou seja, a ampliação da renda nacional leva a uma maior demanda por bens e serviços providos pelo setor público. A segunda é que o comportamento autointeressado dos governantes pode induzi-los a alterar a estrutura fiscal para gerar uma percepção distorcida acerca dos reais preços-tributos desses bens e serviços, isto é, a criar Ilusão Fiscal e, assim, garantir uma maior demanda para alcançar seus próprios objetivos. A última reflete a possibilidade de existir uma relação causal entre receitas e despesas governamentais.

A análise realizada foi baseada na estimação de Modelos Autorregressivos de Defasagens Distribuídas (ARDL) aplicados ao arcabouço da cointegração. Três modelos iniciais foram estimados para explicar a dinâmica dos gastos do governo central e cada um utilizou uma medida diferente para as despesas governamentais: despesas primárias, despesas obrigatórias e despesas discricionárias. Outros três modelos foram estimados para as receitas primárias para identificar o tipo de nexo existente entre as receitas e as diferentes agregações propostas para as despesas.

Os resultados indicaram: i) ausência de validade da Lei de Wagner; ii) presença de efeitos de Ilusão Fiscal relacionados à existência de tributação indireta; iii) uma relação positiva entre endividamento e receitas primárias, que é compatível com o modelo de determinação do endividamento público proposto por Barro (1974) e Barro (1979); e iv) existência de uma relação positiva entre salário mínimo real e a dinâmica das despesas. Por fim, verificou-se que a relação entre receitas e despesas varia conforme se altera a proxy utilizada 
para as despesas. A estimação com os dados agregados aponta para uma relação tax-spend, conforme definida por Buchanan \& Wagner (1977), mas esse resultado pode estar escondendo a verdadeira relação existente para os diferentes tipos de gastos: uma relação spend-tax entre receitas primárias e despesas obrigatórias; e uma relação spend-tax inversa, entre receitas primárias e gastos discricionários.

\section{Agradecimentos}

Pedro Henrique Martins Prado agradece o apoio financeiro da CAPES. Cleomar Gomes da Silva agradece o apoio financeiro do CNPq, CAPES e FAPEMIG.

\section{Referências Bibliográficas}

Akitoby, B., Clements, B., Gupta, S. \& Inchauste, G. (2006), 'Public spending, voracity, and Wagner's Law in developing countries', European Journal of Political Economy 22(4), 908-924.

Araújo, J. M. (2014), Um estudo sobre Ilusão Fiscal no Brasil. Tese de Doutorado, Universidade Federal de Pernambuco.

Araújo, J. M. \& Siqueira, R. B. (2016), 'Demanda por gastos públicos locais: evidências dos efeitos de Ilusão Fiscal no Brasil', Estudos Econômicos 46(1), 189-219.

Baghestani, H. \& Mcnown, R. (1994), 'Revenues or expenditures respond to budgetary disequilibria?', Southern Economic Journal 61(2), 311-322.

Banzhaf, H. S. \& Oates, W. E. (2012), 'On Fiscal Illusion and Ricardian Equivalence in local public finance', National Bureau of Economic Research (W18040), 1-34.

Barro, R. J. (1974), 'Are government bonds net wealth?', Journal of Political Economy 82(6), 1095-1117.

Barro, R. J. (1979), 'On the determination of the public debt', Journal of Political Economy 87(5), 940-971.

Bastiaens, E., Borger, B. \& Vanneste, J. (2001), 'Expenditure and taxation effects of local public debt and unconditional grants: evidence from Flemish municipalities', Brussels Economic Review 17(171), 71-89.

Bayrakdar, S., Demez, S. \& Yapar, M. (2015), 'Testing the validity of Wagner's Law: 1998-2004, the case of Turkey', Procedia-Social and Behavioral Sciences 195, 493-500.

Bertussi, L. A. S. \& Triches, D. (2012), 'Multicointegração e políticas fiscais: uma avaliação de sustentabilidade fiscal para Argentina, Brasil, México, Peru, Uruguai e Venezuela', Revista Economia 13(2), 303-325.

Bird, R. M. (1971), 'Wagner's Law of expanding state activity', Public Finance 26(1), 1-26. 
Brown, R. L., Durbin, J. \& Evans, J. M. (1975), 'Techniques for testing the constancy of regression relationships over time', Journal of the Royal Statistical Society 37(2), 149-192.

Buchanan, J. (1960), Fiscal Theory and Political Economy, University of North Carolina Press, Chapel Hill.

Buchanan, J. (1967), Public Finance in Democratic Process, University of North Carolina Press, Chapel Hill.

Buchanan, J. \& Wagner, R. E. (1977), Democracy in Deficit, Academic Press, New York.

Chang, T. \& Chiang, G. (2009), 'Revisiting the government revenueexpenditure nexus: evidence from 15 OECD countries based on the panel data approach', Czech Journal of Economics and Finance (Finance a Uver) 59(2), 165-172.

Cheng, B. S. (1999), 'Causality between taxes and expenditures: evidence from Latin American countries', Journal of Economics and Finance 23(2), 184192.

Chetty, R., Looney, A. \& Kroft, K. (2009), 'Salience and taxation: theory and evidence', American Economic Review 99(4), 1145-1177.

Christopoulos, D. \& Tsionas, E. (2003), 'Testing the Buchanan-Wagner hypothesis: European evidence from panel unit root and cointegration tests', Public Choice 115(3-4), 439-453.

Courakis, A. S., Moura-Roque, F. \& Tridimas, G. (1993), 'Public expenditure growth in Greece and Portugal: Wagner's Law and beyond', Applied Economics 25(1), 125-134.

Dell'anno, R. \& Mourao, P. (2012), 'Fiscal Illusion around the world: an analysis using the structural equation approach', Public Finance Review 40(2), 270299.

Dollery, B. E. \& Worthington, A. (1995a), 'State expenditure and Fiscal Illusion in Australia: a test of the revenue complexity, revenue elasticity and flypaper hypotheses', Economic Analysis \& Policy 25(2), 125-140.

Dollery, B. E. \& Worthington, A. (1995b), 'The impact of Fiscal Illusion on housing values: an Australian test of the debt illusion hypothesis', Public Budgeting \& Finance 15(3), 63-73.

Dollery, B. E. \& Worthington, A. (1996), 'The empirical analysis of Fiscal Illusion', Journal of Economic Surveys 10(3), 261-297.

Dollery, B. E. \& Worthington, A. (1999), 'Fiscal Illusion at the local level: an empirical test using Australian municipal data', The Economic Record 75(1), 37-48.

Elyasi, Y. \& Rahimi, M. (2012), 'The causality between government revenue and government expenditure in Iran', International Journal of Economic Sciences and Applied Research 5(1), 129-145. 
Engle, R. F., Hendry, D. F. \& Richard, J.-F. (1983), 'Exogeneity', Econometrica 51(2), 277-304.

Friedman, M. (1978), 'The limitations of tax limitation', Quadrant 22(8), 22.

Gadelha, S. R. (2011), 'Causalidade temporal entre receitas e despesas governamentais', Análise Econômica 29(56), 109-130.

Gemmell, N., Morrissey, O. \& Pinar, A. (1999), 'Fiscal Illusion and the demand for government expenditures in the UK', European Journal of Political Economy 15(4), 687-704.

Heyndels, B. \& Smolders, C. (1995), 'Tax complexity and Fiscal Illusion', Public Choice 85(1-2), 127-141.

Jaén-García, M. (2011), 'Empirical analysis of Wagner's Law for the Spain's regions', International Journal of Academic Research in Accounting, Finance and Management Sciences 1(1), 1-17.

Johansen, S. (1992), 'Testing weak exogeneity and the order of cointegration in UK money demand data', Journal of Policy Modeling 14(3), 313-334.

Johansen, S. (1995), Likelihood-based inference in cointegrated vector autoregressive models, Oxford University Press on Demand, Oxford.

Karagianni, S. \& Pempetzoglou, M. (2011), 'Evidence for non-linear causality between public spending and income in the European Union countries', Journal of Applied Business Research (JABR) 25(1), 69-82.

Magazzino, C., Giolli, L. \& Mele, M. (2015), 'Wagner's Law and Peacock and Wiseman's displacement effect in European Union countries: a panel data study', International Journal of Economics and Financial Issues 5(3), 812-819.

Mattos, E. \& Rocha, F. (2001), 'Correção monetária e o equilíbrio do orçamento', Pesquisa e Planejamento Econômico 31(2), 269-288.

Mattos, E. \& Rocha, F. (2011), 'Flypaper effect revisited: evidence for tax collection efficiency in Brazilian municipalities', Estudos Econômicos 41(2), 239267.

Mello, L. (2008), 'Estimating a fiscal reaction function: the case of debt sustainability in Brazil', Applied Economics 40(3), 271-284.

Meltzer, A. H. \& Richard, S. F. (1981), 'A rational theory of the size of government', Journal of Political Economy 89(5), 914-927.

Mendes, M. (2005), 'Capture of fiscal transfers: a study of Brazilian local governments', Economia Aplicada 9(3), 427-444.

Mill, J. S. (1996), Princípios de Economia Política, Os Economistas, Nova Cultura, São Paulo.

Musgrave, R. (1966), Principles of budget determination, in H. Cameron \& W. Henderson, eds, 'Public Finance: Selected Readings', Random House, New York. 
Narayan, P. K. (2005), 'The government revenue and government expenditure nexus: empirical evidence from nine Asian countries', Journal of Asian Economics 15(6), 1203-1216.

Narayan, P. K. \& Narayan, S. (2006), 'Government revenue and government expenditure nexus: evidence from developing countries', Applied Economics 38(3), 285-291.

Narayan, P. K., Nielsen, I. \& Smyth, R. (2008), 'Panel data, cointegration, causality and Wagner's Law: empirical evidence from Chinese provinces', China Economic Review 19(2), 297-307.

Narayan, S., Rath, B. N. \& Narayan, P. K. (2012), 'Evidence of Wagner's Law from Indian states', Economic Modelling 29(5), 1548-1557.

Oates, W. E. (1988), The nature and measurement of Fiscal Illusion: a survey, in G. Brennan, B. Grewel \& S. P. Groenwegen, eds, 'Taxation and Fiscal Federalism: Essays in Honour of Russell Mathews', Australia University Press, Sydney.

Owoye, O. \& Onafowora, O. A. (2011), 'The relationship between tax revenues and government expenditures in European Union and Non-European Union OECD countries', Public Finance Review 39(3), 429-461.

Payne, J. E. (2003), 'A survey of the international empirical evidence on the tax-spend debate', Public Finance Review 31(3), 302-324.

Peacock, A. T. \& Wiseman, J. (1961), The Growth of Public Expenditure in the United Kingdom, Princeton University Press, Princeton.

Peacock, A. T. \& Wiseman, J. (1979), 'Approaches to the analysis of government expenditure growth', Public Finance Review 7(1), 3-23.

Pesaran, M. H. \& Shin, Y. (1998), An autoregressive distributed-lag modelling approach to cointegration analysis, in S. Strom, ed., 'Econometrics and Economic Theory in the 20th Century: The Ragnar Frisch Centennial Symposium', Cambridge University Press, Cambridge.

Pesaran, M. H., Shin, Y. \& Smith, R. J. (2001), 'Bounds testing approaches to the analysis of level relationships', Journal of Applied Econometrics 16(3), 289326.

Puviani, A. (1903), La Teoria della Illusione Finanziaria, Remo Sandon, Milan.

Rahman, S. A. \& Wadud, M. A. (2014), 'Tax and spend, spend and tax, fiscal synchronization or fiscal neutrality: evidence from Bangladesh', The International Journal of Applied Economics and Finance 8(3), 98.

Ricardo, D. (1996), Princípios de Politica Econômica e Taxação, Os Economistas, Nova Cultura, São Paulo.

Sakurai, S. N. (2013), 'Efeitos assimétricos das transferências governamentais sobre os gastos públicos locais: evidências em painel para os municípios brasileiros', Pesquisa e Planejamento Econômico 43(2), 309-332. 
Saunoris, J. W. (2015), 'The dynamics of the revenue-expenditure nexus: evidence from US state government finances', Public Finance Review 43(1), 108 134.

Sausgruber, R. \& Tyran, J. (2005), 'Testing the Mill hypothesis of Fiscal Illusion', Public Choice 122(1), 39-68.

Silva, A. M. A. \& Siqueira, R. B. (2014), 'Demanda por gasto público no Brasil no período pós-redemocratização: testes da hipótese de Mill de Ilusão Fiscal e da Lei de Wagner', Planejamento e Políticas Públicas (43), 45-60.

Silva, C. G., Machado, S. J., Lopes, D. T. \& Rebelo, A. M. (2010), 'Receitas e gastos governamentais: uma análise de causalidade para o caso brasileiro', Economia Aplicada 14(4), 265-275.

Tanzi, V. (2011), Government Versus Markets, Cambridge University Press, Cambridge.

Tasseven, O. (2011), 'The Wagner's Law: time series evidence for Turkey, 1960-2006', Dogus University Journal 12(1), 304-316.

Tobin, D. (2005), 'Economic liberalization, the changing role of the state and Wagner's Law: China's development experience since 1978', World Development 33(5), 729-743.

Turnbull, G. K. (1998), 'The overspending and flypaper effects of Fiscal Illusion: theory and empirical evidence', Journal of Urban Economics 44(1), 126.

Urbain, J.-P. (1992), 'On weak exogeneity in error correction models', Oxford Bulletin of Economics and Statistics 54(2), 187-207.

Wagner, A. H. (1883), Finanzwissenschaft, C F Winter, Leipzig.

Wagner, R. (1976), 'Revenue structure, Fiscal Illusion and budgetary choice', Public Choice 25(1), 45-61.

Wolde-Rufael, Y. (2008), 'The revenue-expenditure nexus: the experience of 13 African countries', African Development Review 20(2), 273-283. 
